\title{
Highly active and reusable catalyst from Fe-Mg-hydrotalcite anionic clay for Friedel-Crafts type benzylation reactions
}

\author{
VASANT R CHOUDHARY*, RANI JHA and PANKAJ A CHOUDHARI \\ Chemical Engineering and Process Development Division, National Chemical Laboratory, Pune 411008 , \\ India \\ e-mail: vrc@chem.ncl.res.in; vrc@ems.ncl.res.in
}

MS received 11 April 2005; revised 20 August 2005

\begin{abstract}
Fe-Mg-hydrotalcite $(\mathrm{Mg} / \mathrm{Fe}=3)$ anionic clay with or without calcination (at $\left.200-800^{\circ} \mathrm{C}\right)$ has been used for the benzylation of toluene and other aromatic compounds by benzyl chloride. Hydrotalcite before and after its calcination was characterized for surface area, crystalline phases and basicity. Both the hydrotalcite, particularly after its use in the benzylation reaction, and the catalyst derived from it by its calcination at $200-800^{\circ} \mathrm{C}$ show high catalytic activity for the benzylation of toluene and other aromatic compounds. The catalytically active species present in the catalyst in its most active form are the chlorides and oxides of iron on the catalyst surface.
\end{abstract}

Keywords. Fe-Mg-hydrotalcite; activation by calcinations; benzylation of toluene; benzylation of aromatic compounds.

\section{Introduction}

Liquid-phase Friedel-Crafts type benzylation of aromatic compounds, using homogeneous catalysts, are the general Friedel-Crafts type reactions used in organic synthesis. ${ }^{1}$ However, the commonly used homogeneous catalysts (viz. $\mathrm{AlCl}_{3}, \mathrm{BF}_{3}$ and $\mathrm{H}_{2} \mathrm{SO}_{4}$ ) pose several problems, such as difficulty in separation and recovery, disposal of spent catalyst, corrosion, high toxicity etc. Moreover, these catalysts are highly moisture-sensitive and hence require moisture-free solvent and reactants and anhydrous conditions, and also dry atmosphere for their handling. A number of highly acidic solid catalysts, such as heteropolyacids, ${ }^{2}$ sulphated $\mathrm{ZrO}_{2}$ or $\mathrm{Fe}_{2} \mathrm{O}_{3},{ }^{3}$ Nafion- $\mathrm{H}^{2}$ and $\mathrm{Fe}$ - and Ga-substituted H-ZSM- $5^{4}$ for benzylation of benzene, HY, H-beta and H-ZSM-5 zeolites for benzylation of toluene $e^{5}$ are reported in the literature. However, the reports on the use of basic catalysts for the benzylation reactions are scarce. ${ }^{6}$

Recently, we have observed high activity of supported basic $\mathrm{In}_{2} \mathrm{O}_{3}$ in these reactions. ${ }^{7}$ Hydrotalcite anionic clays are known to be highly basic solids. ${ }^{8}$ Very recently, we have found that Ga-Mg-hydrotalcite anionic clay, after its first use in the reaction or $\mathrm{HCl}$

*For correspondence gas pretreatment, shows very high activity in the benzylation of toluene and benzene, even in the presence of moisture in the reaction mixture. ${ }^{9,10}$ In the present paper, we report that $\mathrm{Fe}-\mathrm{Mg}$-hydrotalcite shows high activity in the benzylation of toluene and substituted benzene by benzyl chloride ( $\mathrm{ArH}+$ $\mathrm{C}_{6} \mathrm{H}_{5} \mathrm{CH}_{2} \mathrm{Cl} \rightarrow \mathrm{ArCH}_{2} \mathrm{C}_{6} \mathrm{H}_{5}+\mathrm{HCl}$ ). Influence of the calcination (at different temperatures) of the hydrotalcite on its catalytic performance in the benzylation has also been thoroughly investigated.

\section{Experimental}

Fe-Mg-hydrotalcite $(\mathrm{Mg} / \mathrm{Fe}$ mole ratio $=3)$, having a formula: $\left[\mathrm{Fe}_{0.25} \mathrm{Mg}_{0.75}(\mathrm{OH})_{2}\right]^{+0 \cdot 25}\left[\mathrm{CO}_{3}^{2-}\right]_{0.125} \cdot n \mathrm{H}_{2} \mathrm{O}$, was synthesized by the co-precipitation method described earlier. ${ }^{11}$ The hydrotalcite was dried at $80^{\circ} \mathrm{C}$ for $12 \mathrm{~h}$ and this sample is designated as Fe-Mg-HT80. Fe-Mg-HT-200, Fe-Mg-HT-500, and Fe-Mg-HT800 hydrotalcite derived samples were obtained by calcining the $\mathrm{Fe}-\mathrm{Mg}-\mathrm{HT}-80$ at 200,500 and $800^{\circ} \mathrm{C}$, respectively, for $4 \mathrm{~h}$ in a muffle furnace. All these solid samples were characterized for their specific area (using surface area Analyzer, Quantachrome, USA) and also by XRD [using a Philips Diffractometer (1730 series) and $\mathrm{CuK} \alpha$ radiation]. The hydrotalcite (Fe-Mg-HT-80) was characterized by its thermal 
analysis - thermal gravimetric (TG), differential thermal gravimetric (DTG) and differential thermal analysis (DTA) in the presence of static air at a linear heating rate of $10^{\circ} \mathrm{C} / \mathrm{min}$ from $25^{\circ}$ to $900^{\circ} \mathrm{C}$.

The benzylation reactions over the different $\mathrm{Fe}-\mathrm{Mg}$ hydrotalcite based catalysts were carried out in a magnetically stirred glass reactor (capacity: $25 \mathrm{~cm}^{3}$ ) fitted with a reflux condenser, mercury thermometer and arrangement for continuously bubbling moisturefree $\mathrm{N}_{2}\left(30 \mathrm{ml} \mathrm{min}{ }^{-1}\right)$ through the liquid reaction mixture. Before the reaction, the catalyst was refluxed with an aromatic substrate for a period of $0.25 \mathrm{~h}$. The reaction was started by injecting $1.0 \mathrm{ml}$ of benzyl chloride in the reaction mixture, containing $13 \mathrm{ml}$ of liquid aromatic substrate and catalyst $(0.1 \mathrm{~g})$. All the reactions were carried out at 80 or $110^{\circ} \mathrm{C}$ following the procedures described earlier. ${ }^{4,7}$ In all the cases, the product formed in the benzylation was mainly monobenzylated one $\left(\mathrm{ArCH}_{2} \mathrm{C}_{6} \mathrm{H}_{5}, \mathrm{Ar}=\right.$ aromatic substrate group) and there was no formation of polycondensation products, such as poly benzyl chloride. The reaction products were identified by GC.

To study the reusability of the catalyst, the catalyst used in the particular reaction was removed from the reaction mixture by filtration and then washed (with the aromatic substrate) before its reuse in the reaction.

\section{Results and discussion}

\subsection{Characterization of $\mathrm{Fe}-\mathrm{Mg}-\mathrm{HT}$}

The hydrotalcite structure of the synthesized Fe-Mganionic clay material was confirmed by its X-ray analysis (figure 1a); the XRD spectra of the material correspond to that of hydrotalcite. ${ }^{8}$

The hydrotalcite and its solid products of calcination (in air at 200,500 and $800^{\circ} \mathrm{C}$ ) have been characterized for their surface area and basicity (in terms of the $\mathrm{pH}$ of catalyst-water slurry) and crystalline phases (table 1). However, only qualitative information could be obtained on the concentration of various phases (e.g. $\mathrm{MgO}, \mathrm{Fe}_{2} \mathrm{O}_{3}, \mathrm{MgFe}_{2} \mathrm{O}_{4}$ spinel etc.) in the active catalyst.

The Fe-Mg-hydrotalcite was characterized also by its thermal gravimetric (TG) analysis and differential thermal gravimetric (DTG) and differential thermal analysis (DTA) from $25^{\circ}$ to $900^{\circ} \mathrm{C}$, as shown in figure 2. The thermal decomposition of the hydrotalcite occurs in three steps: (1) $12.6 \% \mathrm{wt}$. loss from $25^{\circ}$ to $185^{\circ} \mathrm{C}$, (2) $35.1 \%$ wt. loss from $185^{\circ}$ to $398^{\circ} \mathrm{C}$ and (3) $41.0 \%$ wt. loss from $398^{\circ}$ to $814^{\circ} \mathrm{C}$. The peak maxi- mum temperatures for the observed DTG/DTA peaks are $174^{\circ}$ and $364^{\circ} \mathrm{C}$. The DTA peaks indicate that the decomposition in all the steps is endothermic. The weight loss in the first step is expected owing to the desorption of adsorbed water, whereas that in the second step may be due to the removal of the water of hydration from the hydrotalcite. However, the weight loss in the third step is expected because of the dehydroxylation and decarbonation of the hydrotalcite with the destruction of its structure.

\subsection{Benzylation over Fe-Mg-HT-80}

Results of the benzylation of toluene and other aromatic compounds over the fresh and used (in the respec-

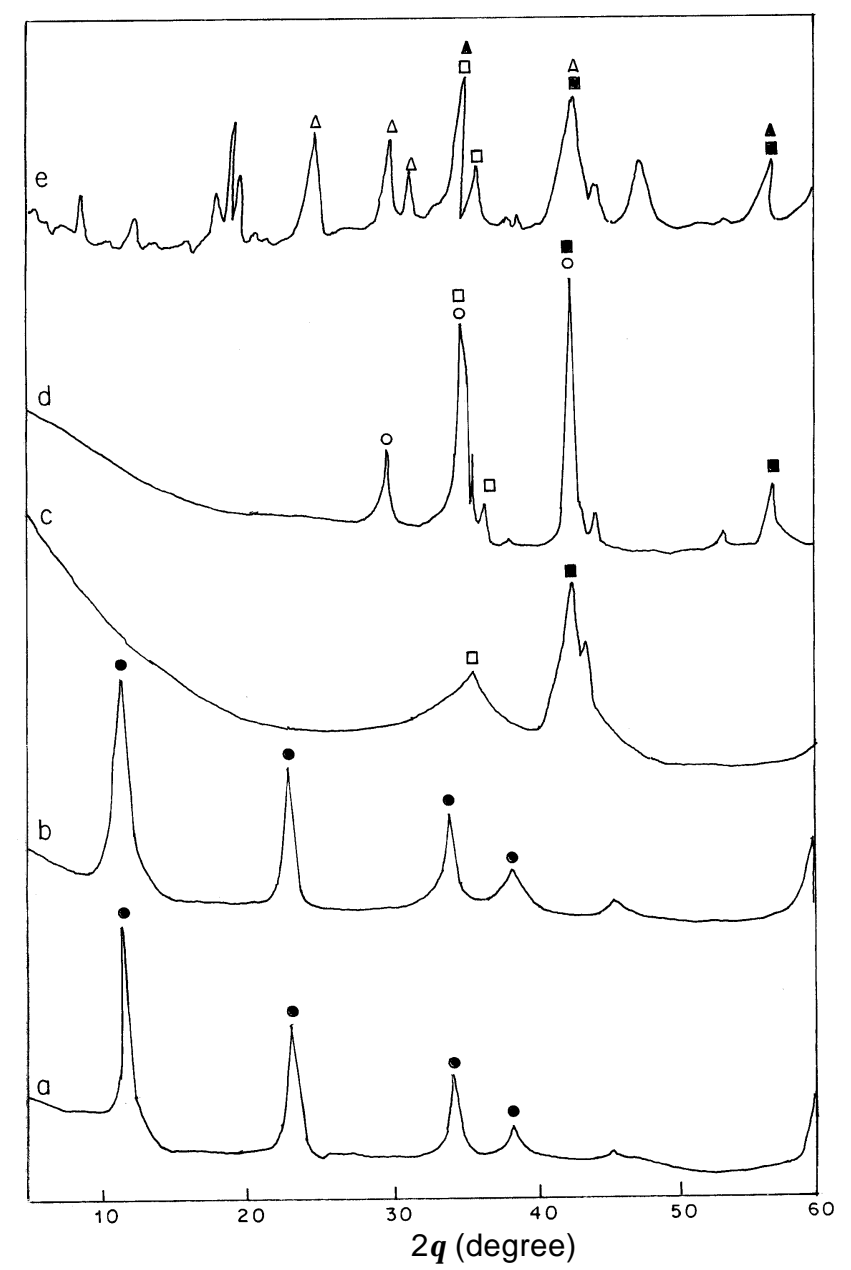

Figure 1. XRD of (a) Fe-Mg-HT-80 (fresh), (b) Fe-MgHT-200 (fresh), (c) Fe-Mg-HT-500 (fresh), (d) Fe-MgHT-800 (fresh) and (e) used Fe-Mg-HT-80 after use in the benzylation of toluene. [Crystalline phases: Pure HT (•), $\mathrm{MgFe}_{2} \mathrm{O}_{4}$ spinel (O), $\mathrm{MgO}(\boldsymbol{\square}), \mathrm{Fe}_{2} \mathrm{O}_{3}(\square), \mathrm{MgCl}_{2}$ (А) and $\mathrm{FeCl}_{3}(\triangle)$.] 
Table 1. Physico-chemical properties of fresh, calcined and used Fe-Mg-HT $(\mathrm{Mg} / \mathrm{Fe}=3)$ catalysts.

\begin{tabular}{|c|c|c|c|c|}
\hline Catalyst & Colour & Surface area $\left(\mathrm{m}^{2} \mathrm{~g}^{-1}\right)$ & $\mathrm{pH}$ of catalyst ${ }^{\mathrm{a}}$ & XRD phases \\
\hline Fresh Fe-Mg-HT-80 & Light brown & 58 & $9 \cdot 6$ & Pure HT \\
\hline Fresh Fe-Mg-HT-200 & Light brown & 70 & $8 \cdot 7$ & Pure HT \\
\hline Fresh Fe-Mg-HT-500 & Pale yellow & 78 & $7 \cdot 8$ & $\mathrm{MgO}$ and $\mathrm{Fe}_{2} \mathrm{O}_{3}$ \\
\hline Fresh Fe-Mg-HT-800 & Pale yellow & 95 & $7 \cdot 6$ & $\mathrm{MgO}, \mathrm{Fe}_{2} \mathrm{O}_{3}$ and $\mathrm{MgFe}_{2} \mathrm{O}_{4}$ \\
\hline Used Fe-Mg-HT-80 & Pale yellow & $32 \cdot 3$ & $7 \cdot 2$ & $\mathrm{MgCl}_{2}, \mathrm{FeCl}_{3}, \mathrm{Fe}_{2} \mathrm{O}_{3}$ and $\mathrm{MgO}$ \\
\hline
\end{tabular}

${ }^{\mathrm{a}} 0 \cdot 15 \mathrm{~g}$ catalyst in $10 \mathrm{ml}$ distilled water

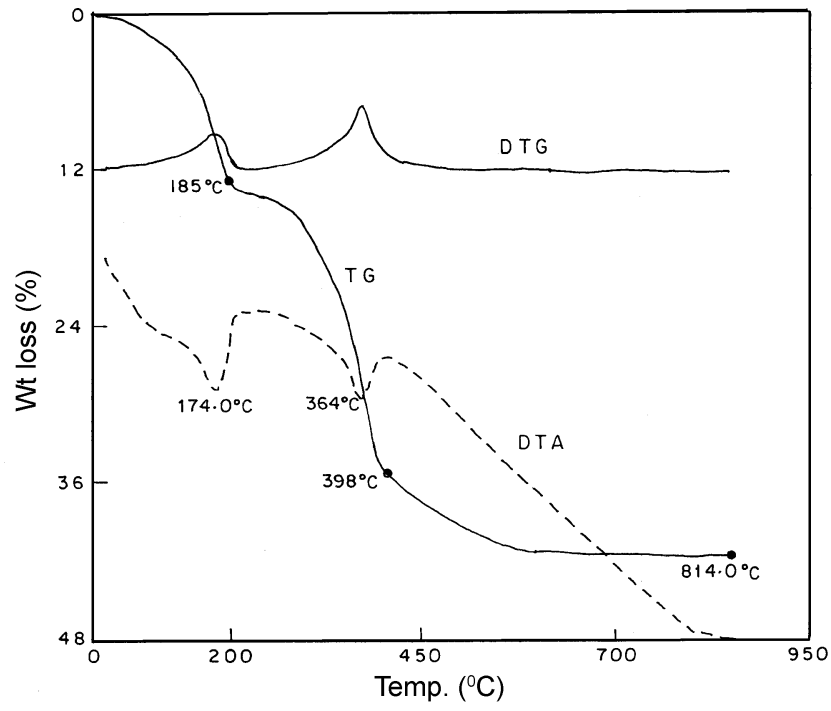

Figure 2. TG, DTG and DTA of Fe-Mg-HT-80 (heating rate $\left.=10^{\circ} \mathrm{C} / \mathrm{min}\right)$.

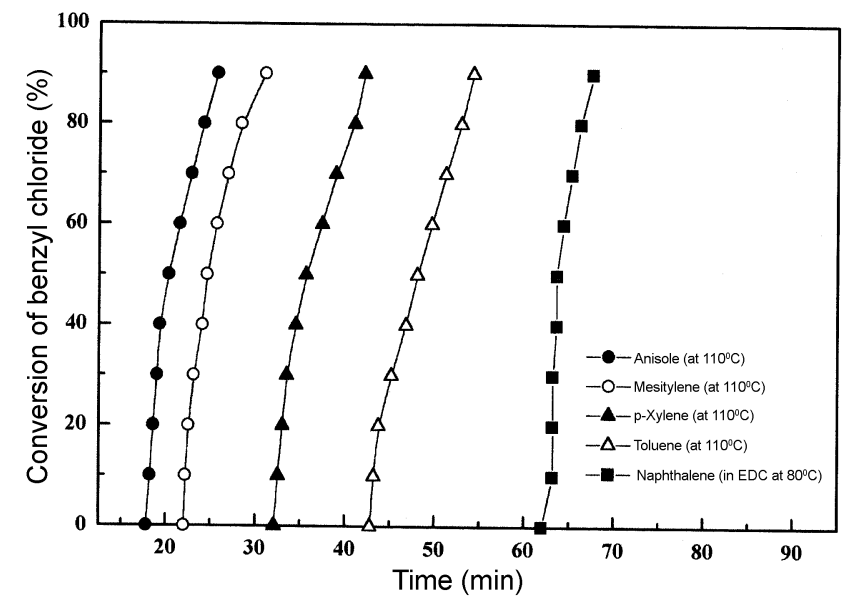

Figure 3. Activity of fresh Fe-Mg-HT-80 catalyst in the benzylation of toluene and other aromatic compounds by benzyl chloride.

tive benzylation reactions at $80^{\circ}$ or $\left.110^{\circ} \mathrm{C}\right) \mathrm{Fe}-\mathrm{Mg}$ HT- 80 are presented in figure 3 and figure 4 , respectively. The results can be summarized as follows:

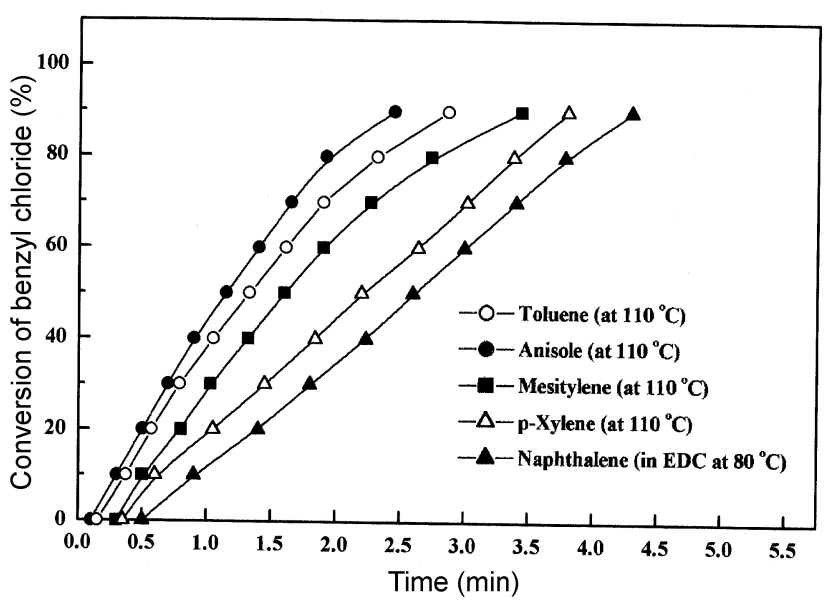

Figure 4. Activity of used Fe-Mg-HT-80 catalyst in the benzylation of toluene and other aromatic compounds by benzyl chloride.

- For the fresh Fe-Mg-HT-80, the reaction induction period is large. However, after the induction period the reaction proceeds at a high rate.

- The reaction induction period is found to depend strongly on the aromatic substrate. The induction period for the benzylation of different aromatic compounds was as follows: anisole $(17.5 \mathrm{~min})<$ mesitylene $(22.0 \mathrm{~min})<p$-xylene $(32.0 \mathrm{~min})<$ toluene $(43.0 \mathrm{~min})<$ naphthalene $(62.5 \mathrm{~min})$.

- Interestingly, the hydrotalcite after it use in the benzylation reaction showed very high benzylation activity (figure 4); the induction period for the benzylation of all the aromatic substrates is reduced drastically.

- Benzylation activity of the used catalyst for different aromatic substrates (measured in terms of time required for half the reaction, $\left.t_{1 / 2}\right)$ is found to be in the following order: anisole $\left(t_{1 / 2}=1.1 \mathrm{~min}\right)<$ toluene $(1.3 \mathrm{~min})<$ mesitylene $(1.6 \mathrm{~min})<p$-xylene $(2.2 \mathrm{~min})$ $<$ naphthalene $(2.6 \mathrm{~min})$.

The XRD of the used catalyst (table 1) showed the presence of crystalline phases (viz. $\mathrm{Fe}_{2} \mathrm{O}_{3}, \mathrm{MgO}$, 
$\mathrm{MgCl}_{2}$ and $\mathrm{FeCl}_{3}$ ) different from that observed for the fresh Fe-Mg-HT-80. This clearly shows a phase transformation and/or structural breakdown for the hydrotalcite during its use in the reaction, mainly by the $\mathrm{HCl}$ produced in the reaction. The basicity of the hydrotalcite also decreases after its use in the reaction (table 1). It would be interesting to know the activity of chloride anion exchanged Fe-Mg-HT. This study will be carried out later.

The observed high benzylation activity of the hydrotalcite after the induction period is therefore attributed to the formation of catalytically active species (viz. $\mathrm{Fe}_{2} \mathrm{O}_{3}$ and $\mathrm{FeCl}_{3}$ ) on the surface of the hydrotalcite during the induction period by the interaction of benzyl chloride and $\mathrm{HCl}$ (formed in the initial reaction) with the basic hydrotalcite. The $\mathrm{HCl}$ formed in the benzylation reaction is responsible for the structural breakdown of the hydrotalcite.

The induction period for the different aromatic substrates is different (figure 3). This is attributed to a difference in the reactivity of the aromatic substrates with benzyl chloride on the catalyst. It is interesting to note from the results in figure 4 that the rate of benzylation shows no expected (by the classical Friedel-Crafts mechanism) dependence on the presence of different electron donating group(s) in the aromatic substrate; the rate of toluene benzylation is much higher than that of the mesitylene or $p$ xylene benzylation. Thus, the classical Friedel-Crafts mechanism does not simply hold good in the present catalytic system. This is consistent with that observed earlier in case of the benzylation of substituted benzenes over supported $\mathrm{In}_{2} \mathrm{O}_{3}, \mathrm{Ga}_{2} \mathrm{O}_{3}, \mathrm{GaCl}_{3}$ and $\mathrm{InCl}_{3}$ catalysts. ${ }^{7,12-14}$

\subsection{Effect of calcination temperature of $\mathrm{Fe}-\mathrm{Mg}-\mathrm{HT}$}

Results showing the influence of calcination temperature of the $\mathrm{Fe}-\mathrm{Mg}-\mathrm{HT}$ catalyst on its performance in the benzylation of toluene at $110^{\circ} \mathrm{C}$ are presented in figure 5 . The results can be summarized as follows:

- Increase in the calcination temperature causes a large decrease in the reaction induction period, depending upon the temperature; higher the calcination temperature, lower the induction period $(43 \cdot 0,11 \cdot 5$, 4.3 and $1.5 \mathrm{~min}$ for the catalyst calcined at 80,200 , 500 and $800^{\circ} \mathrm{C}$, respectively).

- Benzylation activity of the catalyst is increased markedly on increasing its calcination temperature; the time for half the reaction (measured in terms of $t_{1 / 2}$ ) is $48 \cdot 1,13.0,6 \cdot 0$ and $2.5 \mathrm{~min}$ for the catalyst calcined at $80,200,500$ and $800^{\circ} \mathrm{C}$ respectively.

The results clearly show that the activation of the hydrotalcite catalyst for the benzylation reaction depend strongly upon the calcination temperature. Catalyst activation is expected because of the dehydration and/or decomposition of the Fe-Mg-HT-80 followed by the formation of single and/or mixed metal oxide phases, as shown by the XRD spectra of the hydrotalcite calcined at different temperatures (table 1). The surface area of the catalyst also increases with increasing calcination temperature. However, the very large increase in the benzylation activity of the catalyst with the increase in calcination temperature cannot be attributed merely to the observed increase in the catalyst surface area. It is attributed mainly to the dehydration (at $200^{\circ} \mathrm{C}$ ) and/or formation of catalytically active metal oxide species during calcination (at $\geq 500^{\circ} \mathrm{C}$ ).

After the calcination at $200^{\circ} \mathrm{C}$, the hydrotalcite structure is retained but the XRD peaks are broadened. However, after calcination at $500^{\circ} \mathrm{C}$, the hydrotalcite structure is destroyed with the formation of metal oxide $\left(\mathrm{MgO}\right.$ and $\left.\mathrm{Fe}_{2} \mathrm{O}_{3}\right)$ phases. In the calcination at $800^{\circ} \mathrm{C}$, two distinct phases, $\mathrm{MgO}$ and $\mathrm{MgFe}_{2} \mathrm{O}_{4}$ (spinel), are formed. This is consistent with that observed earlier. ${ }^{15}$ The activation of the Fe-Mg-HT- 80 by its calcination at $200^{\circ} \mathrm{C}$ is expected because of the removal of the water of hydration present in the parent hydrotalcite, resulting in an increase in the surface

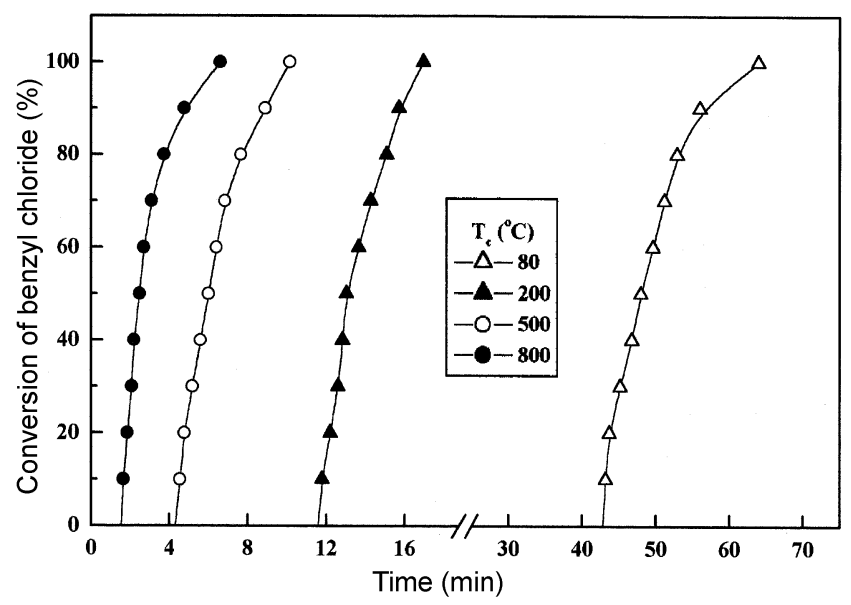

Figure 5. Influence of calcination temperature $\left(T_{c}\right)$ of $\mathrm{Fe}-\mathrm{Mg}$-HT on its activity in the benzylation of toluene (at $110^{\circ} \mathrm{C}$ ) by benzyl chloride. 
area (from 58 to $70 \mathrm{~m}^{2} \mathrm{~g}^{-1}$ ). The activation of the hydrotalcite by its calcination at the higher temperature is attributed to both the removal of the water of hydration from the catalysts and the formation of single and/or mixed metal oxide phases such as finely dispersed $\mathrm{Fe}_{2} \mathrm{O}_{3}$ on $\mathrm{MgO}$ (formed at $500^{\circ} \mathrm{C}$ ) or finely dispersed $\mathrm{MgFe}_{2} \mathrm{O}_{4}$ on $\mathrm{MgO}$ (formed at $800^{\circ} \mathrm{C}$ ), with increase in the surface area.

\section{Conclusions}

Fe-Mg-hydrotalcite $(\mathrm{Mg} / \mathrm{Fe}=3)$ showed high activity in the benzylation of toluene and other aromatic compounds (anisole, mesitylene, $p$-xylene and naphthalene). After its use in the benzylation, the reaction induction period for the benzylation of toluene and other aromatic compounds is drastically reduced. During the reaction the hydrotalcite is structurally collapsed with the formation of metal chlorides and oxides. Upon its calcination at higher temperature $\left(\geq 300^{\circ} \mathrm{C}\right)$, the calcined hydrotalcite shows high benzylation activity; its benzylation activity increases with increase in the calcination temperature. Catalyst activation due to the calcination at different temperatures $\left(T_{c}\right)$ is attributed to dehydration (for $T_{c}=$ $200^{\circ} \mathrm{C}$ ), formation of metal oxides (for $T_{c}=500^{\circ} \mathrm{C}$ ) or $\mathrm{MgO}$ and $\mathrm{MgFe}_{2} \mathrm{O}_{4}$ (for $T_{c}=800^{\circ} \mathrm{C}$ ), causing successive increases in surface area. For the catalyst (hydrotalcite or derived from hydrotalcite) in its most active form, the catalytically active species for benzylation are the finely dispersed $\mathrm{FeCl}_{3}$ and $\mathrm{Fe}_{2} \mathrm{O}_{3}$ on $\mathrm{MgO}$.

\section{Acknowledgments}

RJ is grateful to Council of Scientific and Industrial Research, New Delhi for the award of a Fellowship. The authors are grateful to Dr A Mitra for XRD work.

\section{References}

1. Olah G A 1963 Friedel-Crafts and related reactions, 1 (New York: Wiley-Interscience) p. 32

2. Yusuke I, Mayumi O and Kazuo U 1995 Appl. Catal. A132 127

3. Koyande S N, Jaiswal R G and Jayaram R V 1998 Ind. Eng. Chem. Res. 37908

4. Choudhary V R, Jana S K and Kiran B P 1999 Catal. Lett. 59217

5. Coq B, Gourves V and Figueras F 1993 Appl. Catal. A100 69

6. Ono Y and Baba T 1997 Catal. Today 38321

7. Choudhary V R, Jana S K and Kiran B P $2000 \mathrm{~J}$. Catal. 192257

8. Cavani F, Trifiro F and Vaccari A 1991 Catal. Today 11173

9. Choudhary V R, Jana S K and Mandale A B 2001 Catal. Lett. $\mathbf{7 4} 95$

10. Choudhary V R, Jana S K and Narkhede V S 2002 Appl. Catal. A235 207

11. Lopez-Salinas E, Garcia-Sanchez M, Ramon-Garcia M L and Scifter I 1996 J. Porous Mater. 3169

12. Choudhary V R, Jana S K, Patil N S and Bhargava S K 2003 Micropor. Mesopor. Mater. 5721

13. Choudhary V R and Jana S K 2002 J. Mol. Catal. A184 247

14. Choudhary V R and Jana S K 2002 J. Mol. Catal. A180 267

15. Lopez-Salinas E, Torres-Garcia E and GarciaSanchez M 1997 J. Phys. Chem. Solids 58919 